\title{
PGM2 overexpression improves anaerobic galactose fermentation in Saccharomyces cerevisiae
}

\author{
Rosa Garcia Sanchez, Bärbel Hahn-Hägerdal and Marie F Gorwa-Grauslund*
}

\begin{abstract}
Background: In Saccharomyces cerevisiae galactose is initially metabolized through the Leloir pathway after which glucose 6-phosphate enters glycolysis. Galactose is controlled both by glucose repression and by galactose induction. The gene PGM2 encodes the last enzyme of the Leloir pathway, phosphoglucomutase 2 (Pgm2p), which catalyses the reversible conversion of glucose 1-phosphate to glucose 6-phosphate. Overexpression of $P G M 2$ has previously been shown to enhance aerobic growth of $S$. cerevisiae in galactose medium.

Results: In the present study we show that overexpression of PGM2 under control of the HXT7'promoter from an integrative plasmid increased the PGM activity 5 to 6 times, which significantly reduced the lag phase of glucosepregrown cells in an anaerobic galactose culture. PGM2 overexpression also increased the anaerobic specific growth rate whereas ethanol production was less influenced. When PGM2 was overexpressed from a multicopy plasmid instead, the PGM activity increased almost 32 times. However, this increase of PGM activity did not further improve aerobic galactose fermentation as compared to the strain carrying PGM2 on the integrative plasmid.

Conclusion: PGM2 overexpression in S. cerevisiae from an integrative plasmid is sufficient to reduce the lag phase and to enhance the growth rate in anaerobic galactose fermentation, which results in an overall decrease in fermentation duration. This observation is of particular importance for the future development of stable industrial strains with enhanced PGM activity.
\end{abstract}

\section{Background}

Sustainable bioconversion of renewable lignocellulose raw material requires that all sugar components are efficiently utilized [1]. These raw materials are composed of a number of different monosaccharides one of which is galactose. It may constitute up to $18 \%$ of the total released monomeric sugar of pretreated softwood [2]. Actually the amount of galactose is higher than that of arabinose in certain raw materials such as willow [3] and spruce [4]. Galactose also makes up a substantial amount of other industrial media raw materials as beet molasses [5] and cheese whey [6].

Baker's yeast, which is the preferred organism for industrial ethanolic fermentation [7], catabolizes galactose via the Leloir pathway [8]. Galactose catabolism to the glycolytic intermediate glucose 6-phosphate is a complex sequence of reactions including phosphorylation and

* Correspondence: Marie-Francoise.Gorwa@tmb.Ith.se

1 Department of Applied Microbiology, Lund University, P.O. Box 124, SE-22100 Lund, Sweden

Full list of author information is available at the end of the article group transfer. Galactose is consumed and metabolized at a significantly lower rate than glucose since it delays induction of glycolytic genes [9]. In addition the Leloir pathway is controlled by glucose repression even in the presence of galactose [10].

When the structural genes for the galactose metabolizing enzymes were overexpressed, growth on galactose was impaired [11]. However increased galactose utilization and ethanol production was observed when genes encoding the galactose regulatory network were engineered [12]. A transcriptome analysis of two of these engineered S. cerevisiae strains, SO7 (pGAL4, $2 \mu$ ) and SO16 ( $\triangle$ gal6 $\Delta$ gal80 $\Delta$ mig1), later identified a slight upregulation of PGM2 (GAL5) to be a common denominator [13]. It was also verified that overexpression of $P G M 2$ in S. cerevisiae improved galactose uptake under aerobic conditions while anaerobic conditions were not investigated [13].

The objective of the current study was to investigate the influence of overexpressing PGM2 in S. cerevisiae under anaerobic conditions. PGM2 was expressed both from a 
multicopy plasmid and from an integrative plasmid. The PGM activity increased 5 to 6 -fold in galactose-grown cells when the gene was expressed from the integrative plasmid. PGM2 overexpression reduced the lag phase of glucose pre-grown cells and increased the maximum specific growth rate on galactose. The additional increase of PGM activity in strains expressing PGM2 from a multicopy plasmid did not further increase growth on galactose.

\section{Results}

\section{Effect of PGM2 gene dosage}

Two strains with different copy numbers of the gene $P G M 2$ were constructed in the same genetic background (Table 1). In both strains, PGM2 was expressed under the control of the constitutive promoter $H X T 7^{\prime}$ [14]. One strain expressed at least one additional integrated copy of PGM2 and was named PGM2 i. Its corresponding control strain was Control i. The other constructed strain overexpressed PGM2 from a multicopy plasmid and was named PGM2 $\mathbf{m}$. Its control strain Control $\mathbf{m}$ carried the same plasmid without the structural gene.

The effect of the PGM2 copy number on the specific PGM activity was assessed in crude extracts of cells grown on galactose (Table 2). Strains Control $\mathbf{m}$ and Control i displayed the same specific PGM activity, 0.33 and $0.34 \mathrm{U} \mathrm{mg}^{-1}$ protein, respectively, whereas the specific activity in the PGM2 $\mathbf{m}$ and PGM2 i strains increased to 10.40 and $1.81 \mathrm{U} \mathrm{mg}^{-1}$ protein, respectively. Whereas PGM activity increased almost 32 fold in the multicopy strain, only a 17 fold increase was observed in the previously reported overexpression of PGM2 on multicopy vector [13] (Table 2). The difference may be ascribed to different strain background, different multicopy vector and different promoter.

Next, the PGM2 overexpressing strains and their respective control strains were compared with respect to aerobic growth in galactose medium (Table 2, Figure 1). In aerobiosis on galactose, growth, galactose consumption and ethanol production were similar for the two control strains, Control $\mathbf{m}$ and Control i (Figure 1). Also the strains overexpressing PGM2, from a multicopy plasmid, PGM2 $\mathbf{m}$, and from an integrated plasmid, PGM2 i, respectively, displayed similar results (Figure 1). The maximum specific growth rates $\left(\mu_{\max }\right)$ were $0.22 \pm 0.01$ and $0.24 \pm 0.02 \mathrm{~h}^{-1}$ for strains Control $\mathbf{m}$ and Control i respectively, whereas $\mu_{\max }$ for strains PGM2 $\mathbf{m}$ and PGM2 $\mathrm{i}$ increased to $0.30 \pm 0.02$ and $0.32 \pm 0.01 \mathrm{~h}^{-1}$, respectively. Despite the fact that strain PGM2 $\mathbf{m}$ had 5 to 6 times higher PGM activity than strain PGM2 $\mathrm{i}$ when grown in galactose, $\mu_{\max }$ did not increase significantly. It was therefore decided to further investigate the influence of increased PGM activity only for strain PGM2 $\mathbf{i}$ and its control strain Control i. Additionally the fact that the extra-copy of PGM2 was stably integrated in the genome of the PGM2 i strain enabled us to study the effect of PGM2 overexpression independently of variations in plasmid copy number.

When the strains Control $\mathbf{i}$ and PGM2 $\mathbf{i}$ were grown aerobically in glucose medium $\mu_{\max }$ was $0.36 \pm 0.01 \mathrm{~h}^{-1}$ and $0.37 \pm 0.04 \mathrm{~h}^{-1}$, respectively, which showed that the additional copy of the PGM2 gene did not affect growth on glucose. Assuming that the maximum specific growth rate on glucose $\left(0.37 \mathrm{~h}^{-1}\right)$ is also the theoretical maximum specific growth rate on galactose, overexpression of $P G M 2$ results in a significant contribution to obtaining that growth rate.

\section{Anaerobic fermentation of galactose}

Anaerobic fermentation of galactose with the strains Control i and PGM2 i, showed that overexpressing PGM2 reduced the time required to deplete galactose with about $24 \mathrm{~h} \pm 1 \mathrm{~h}$ (Figure 2A and 2B). The increased PGM activity consistently reduced the lag phase of fermentative galactose-grown cells (pre-cultivated on glucose) (Figure 2). This was accompanied by an increase of the maximum specific growth rate from $0.098 \mathrm{~h}^{-1} \pm 0.003$ to $0.139 \mathrm{~h}^{-1} \pm$ 0.004 (p-value $<0.01$ ) (Table 3). The ratio between the different products of galactose was much less influenced by the increased PGM activity. The ethanol yield was the same for strains Control i and PGM2 i. However, the reduced lag phase and the increased maximum specific growth rate translated into a shorter fermentation duration from $69.3 \pm 0.8 \mathrm{~h}$ in the Control i strain to $45.5 \pm 0.4$ in the PGM2 i strain.

\section{Discussion}

The present study demonstrates for the first time that the introduction in the chromosome of an additional copy of the gene PGM2 encoding Pgm2p under the control of a strong and constitutive promoter increased the maximum specific growth rate on galactose in anaerobic fermentation. In addition the lag phase of glucose-pregrown cells in anaerobic galactose medium was significantly reduced. The extra integrated copy of the gene PGM2 increased the PGM activity 5 to 6 times in galactosegrown cells. Further overexpression of PGM2 from a multicopy plasmid increased the PGM activity almost 32 times as compared to the control strain but this did not further increase aerobic growth on galactose compared with overexpression from an extra chromosomal copy.

Pgm2p catalyses the last step in the Leloir pathway [8] where glucose 1-phosphate (G1P) is reversibly converted to the glycolytic intermediate glucose 6-phosphate (G6P). Pgm2p is the major isoform of the PGM enzyme in S. cerevisiae accounting for 80 to $90 \%$ of the PGM activity $[15,16]$. Pgm2p was originally believed to be constitu- 
Table 1: Plasmids and S. cerevisiae strains used in this study

\begin{tabular}{llc}
\hline & Relevant genotype/phenotype & Reference \\
\hline & & \\
\hline Plasmids & YEplac195, HXT7P-PGKt URA3 & [27] \\
\hline YEplacHXT & YEplac195, HXT7p-PGM2-PGKt URA3 & This work \\
\hline YEplacHXT-PGM2 & HIS3 & [33] \\
\hline YDp-H & URA3 & [30] \\
\hline YIplac211 & Ylpac211, HXT7p-PGM2-PGKt URA3 & This work \\
\hline Ylplac211 HXT-PGM2
\end{tabular}

\begin{tabular}{|c|c|c|}
\hline S. cerevisiae strains $\left({ }^{*}\right)$ & & \\
\hline CEN.PK 113-11C & MATa his3 11 ura 3-52 MAL2-8c SUC2 & {$[28]$} \\
\hline TMB 3126 & CEN.PK 113-11C, his3 1 YEplacHXT URA3 & This work \\
\hline TMB 3400 & genomic S. cerevisiae DNA (used as template to amplify PGM2) & [29] \\
\hline TMB 3127 & CEN.PK 113-11C, his3 $\triangle 1$ YEplacHXT-PGM2 URA3 & This work \\
\hline TMB 3128 "Control m" & TMB 3126 his3::HIS3 YEplacHXT URA3 & This work \\
\hline TMB 3129 "PGM2 m" & TMB 3127 his3::HIS3 YEplacHXT-PGM2 URA3 & This work \\
\hline TMB 3134 & CEN.PK 113-11C, his3::HIS3 ura3 & This work \\
\hline TMB 3135 "Control i" & CEN.PK 113-11C, his3::HIS3 ura3::URA3 & This work \\
\hline TMB 3136 "PGM2 i" & CEN.PK 113-11C, his3::HIS3 ura3::URA3 HXT7'p-PGM2-PGKt & This work \\
\hline
\end{tabular}

$\left({ }^{*}\right)$ Abbreviations of the most important genetic features are shown in quotation marks

tively present in high levels [10,15]. However, it was later found that the exposure to galactose gives lower induction of Pgm2p activity compared to other structural GAL genes that are at least 1000 -fold induced $[10,16]$. The fact that overexpression of PGM2 under a strong constitutive promoter enhanced growth on galactose indicates that PGM is a controlling enzyme in the Leloir pathway.

Overexpression of PGM2 has previously been shown to increase the galactose uptake rate and the specific growth rate under aerobic conditions [13]. In the current study we confirmed these results in another strain background. When compared with the results of Bro et al, higher specific growth rates on galactose were obtained for both the control strains and the PGM2 overexpressing strains under aerobiosis. However higher concentrations of galactose were used in the present study. Nevertheless, in both studies the aerobic specific growth rates on galactose increased by $33-36 \%$ when the overexpressing PGM2 
Table 2: Specific PGM activity (U mg protein $^{-1}$ ) and maximum specific growth rates on galactose

\begin{tabular}{|c|c|c|}
\hline Strain & $\begin{array}{c}\text { PGM activity } \\
\text { (U mg protein-1) }\end{array}$ & $\begin{array}{l}\text { Maximum specific growth rates } \\
(\mathrm{h}-1)\end{array}$ \\
\hline Control m & $0.33 \pm 0.03$ & $0.22 \pm 0.01$ \\
\hline PGM2 m & $10.40 \pm 1.58$ & $0.30 \pm 0.02$ \\
\hline Control i & $0.34 \pm 0.01$ & $0.24 \pm 0.02$ \\
\hline PGM2 i & $1.81 \pm 0.47$ & $0.32 \pm 0.01$ \\
\hline Reference strain [13] & $0.14 \pm 0.02$ & $0.17 \pm 0.01$ \\
\hline CB2 strain (pPMA1'p PGM2 $2 \mu$ ) [13] & 2.38 & $0.23 \pm 0.02$ \\
\hline
\end{tabular}

gene was overexpressed. We also found that, in our strain background, the increased PGM activity brought the aerobic specific growth rate in $50 \mathrm{~g} \mathrm{l}^{-1}$ galactose medium, $0.32 \mathrm{~h}^{-1}$, close to that in $20 \mathrm{~g} \mathrm{l}^{-1}$ glucose medium, $0.37 \mathrm{~h}^{-1}$.

Absence of anaerobic growth on galactose has been frequently observed for S. cerevisiae [17-19] and it has recently been ascribed to low cellular energy charge [18]. In the present study, an increased PGM activity resulted in improved anaerobic galactose utilization, which indicated that the energy charge deficiency may not be the only limitation of the Leloir pathway. For instance PGM upregulation has been shown to increase the intracellular levels of glucose 6-phosphate $[11,13,20]$ that is known to activate glycolysis $[9,21,22]$.

\section{Conclusions}

Chromosomal integration of an additional copy of the PGM2 gene was sufficient to increase the anaerobic growth rate with $42 \%$ and reduce the fermentation time by $34 \%$. Chromosomal integration allows for the construction of stable industrial strains that are expected to decrease the ethanol production time. These results have practical implications for industrial ethanolic fermentation of raw materials containing galactose, such as raffinose from the sugar industry [5], whey from the dairy industry [6] and lignocellulose for fuel ethanol production [2-4].

\section{Methods}

\section{Strains}

Escherichia coli DH5 $\alpha$ and JM101 (Life Technologies, Rockville, MD, USA) were used for cloning. Plasmids and
Saccharomyces cerevisiae strains (Table 1) were stored at $-80^{\circ} \mathrm{C}$ in $15 \%$ glycerol. Freshly streaked plates from frozen stocks were used to inoculate pre-cultures.

\section{Molecular biology techniques}

Standard molecular biology techniques were used for cloning [23]. Restriction enzymes, T4-DNA ligase and Shrimp Alkaline Phosphatase (SAP) were obtained from Fermentas (Vilnius, Lithuania). Yeast genomic DNA was purified with Easy-DNA Kit (Invitrogen, Groningen, The Netherlands). Escherichia coli DH5 $\alpha$ competent cells were prepared as described before [24] and transformed using the calcium chloride method [25]. Yeast was transformed with the lithium acetate method [26]. Plasmids were extracted from bacteria either with GeneJET TM (Fermentas, Vilnius, Lithuania) or with QIAGEN Mini Plasmid Purification kit (Qiagen GmbH, Hilden, Germany). The QIAquick kit was used for Gel Extraction of DNA fragments from agarose gel as well as for PCR purification of amplified DNA products. Taq-polymerase (Fermentas, Vilnius, Lithuania) was used for analytical PCR, while Pfu-polymerase (Fermentas, Vilnius, Lithuania) and Pwo-polymerase (Roche Diagnostics GmbH, Mannheim, Germany) were used for High-fidelity PCR. Abi-Prism Big-Dye cycle sequencing kit (Applied Biosystems, Weiterstadt, Germany) was used for DNA sequencing that was performed by $\mathrm{BM}$ labbet $\mathrm{AB}$ (Furulund, Sweden).

\section{Construction of strains expressing multiple copies of the PGM2 gene}

The YEplacHXT vector [27] that enables strong constitutive expression under the yeast promoter $H X T 7^{\prime}$ [14] was 

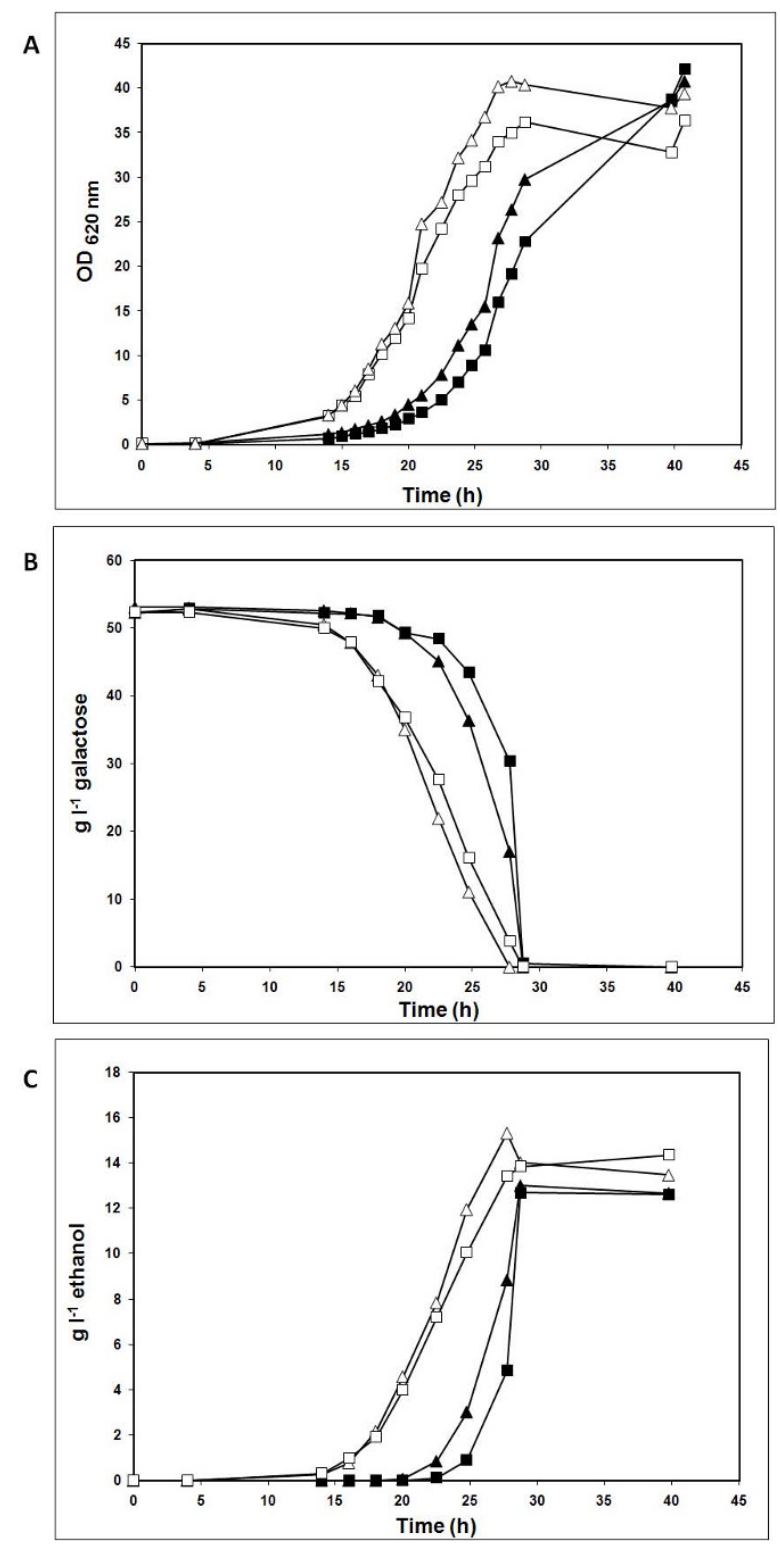

Figure 1 Effect of PGM level on aerobic growth on galactose. Aerobic batch with YNB medium supplemented with $50 \mathrm{~g} \mathrm{l}^{-1}$ galactose. Inocula pre-grown on YNB medium with $20 \mathrm{~g} \mathrm{l}^{-1}$ glucose. Experiments were performed in duplicate. (A) Biomass formation $\left(\mathrm{OD}_{620 \mathrm{~nm}}\right)$. (B) Galactose consumption. (C) Ethanol production. S. cerevisiae strains: Control m (filled square), PGM2 m (open square), Control i (filled triangle) and PGM2 i (open triangle).

linearized between the $H X T 7$ 'promoter and PGK terminator using BamHI and PstI. Transformation of S. cerevisiae CEN.PK 113-11C [28] with the cleaved vector YEplacHXT generated strain TMB 3126 (Table 1). In parallel, the PGM2 gene was amplified from genomic DNA from TMB 3400 (Table 1) [29] using primers with overhangs (in bold) homologous to the 3 ' region of the HXT7'promoter(5'TTTTTTAATTTTAATCAAAAA AGGATCCCCGGGCTGCAATGTCATTTCAATT-
GAAACG-3') and the 5 ' region of the $P G K$ terminator (5'CCACCACCAGTAGAGACATGGGAGATCTAGA ATTCCTTTAAGTACGAACCGTTGG-3'). The amplified fragment and the linearized plasmid were introduced in CEN.PK 113-11C to form the plasmid YEplacHXTPGM2 by recombination (Table 1) and generated strain TMB 3127 (Table 1). The histidine auxotrophy of strains TMB 3216 and TMB 3127 was complemented by transforming the strains with a linear fragment containing the HIS3 locus that was amplified from YDp-H plasmid (Berben, Dumont et al. 1991) and selecting for growth in defined mineral medium without supplementation. The resulting strains were named Control $\mathbf{m}$ and PGM2 m, respectively (Table 1 ).

Plasmids were rescued and transformed into E. coli DH5 $\alpha$ for verification. Analytical PCR of recovered plasmids confirmed that extra copies of PGM2 under the HXT7p' were present in PGM2 m but not in the Control m strain.

\section{Genomic integration of $P G M 2$}

The HIS3 amplicon was first transformed into S. cerevisiae CEN.PK 113-11C and transformants were selected on defined mineral medium supplemented with uracil. The resulting strain TMB 3134 (Table 1) was used to construct the strains Control i, TMB 3135 and PGM2 i, TMB 3136 (Table 1) as follows. The purified plasmid YEplacHXT-PGM2 (Table 1) from strain PGM2 $\mathbf{m}$ was used as template to PCR amplify the amplicon $H X T 7^{\prime} p$ PGM2-PGKt using Pwo-polymerase and the following primers: PGKSalI (5' ATCTGTCGACGACATAGAAATATCGAATGG 3 ') with sequence homologous to PGKt (in bold) and HXTSalI (5' ATCTGTCGACAGGAACAATTTCGGGCC 3 ') with sequence homologous to HXT7'p (in bold). The PCR product $H X T 7^{\prime} p-P G M 2-$ $P G K t$ and the integrative vector YIplac211 [30] were cleaved with restriction enzyme SalI and ligated. The ligation mixture was transformed into E. coli $\mathrm{DH} 5 \alpha \mathrm{com}$ petent cells and transformants were selected on LB plates with $100 \mathrm{mg} \mathrm{l}^{-1}$ ampicillin. PCR and restriction analyses were used to confirm the proper size of the resulting plasmid YIplac211 HXT-PGM2.

Purified plasmids YIplac211 and YIplac211 HXTPGM2 (Table 1) from E. coli were cleaved with EcoRV to target the URA3 locus in strain TMB 3134. The prototrophic strain Control $\mathbf{i}$ and PGM2 $i$ were generated by integration of cleaved YIplac211 and YIplac211 HXTPGM2 (Table 1), respectively. Genomic integration of $H X T 7^{\prime} p$-PGM2-PGKt was verified by analytical PCR of genomic DNA.

\section{Aerobic cultivation conditions}

E. coli was grown and selected on Luria-Bertani medium (LB) [23] with $100 \mathrm{mg} \mathrm{l}^{-1}$ ampicillin. 
Table 3: Parameters analyzed during anaerobic batch fermentation of galactose.

\begin{tabular}{cccccc}
\hline Strain & $\begin{array}{c}\text { Maximum specific growth rate } \boldsymbol{\mu}_{\max } \\
(\mathbf{h}-\mathbf{1}) \mathbf{a}\end{array}$ & $\begin{array}{c}\text { Biomass yield } \\
(\mathbf{g} \text { g galactose } \mathbf{- 1})\end{array}$ & $\begin{array}{c}\text { Glycerol yield } \\
(\mathbf{g} \text { g galactose-1) }\end{array}$ & $\begin{array}{c}\text { Ethanol yield } \\
(\mathbf{g} \text { g galactose } \mathbf{- 1})\end{array}$ & $\begin{array}{c}\text { Fermentation time } \\
\text { (h) }\end{array}$ \\
\hline Control $\mathbf{i}$ & $0.098 \pm 0.003$ & $0.08 \pm 0.00$ & $0.07 \pm 0.01$ & $0.41 \pm 0.02$ & $69.3 \pm 0.8$ \\
\hline PGM2 i & $0.139 \pm 0.004$ & $0.09 \pm 0.01$ & $0.09 \pm 0.01$ & $0.41 \pm 0.02$ & $45.5 \pm 0.4$ \\
\hline
\end{tabular}

aMaximum specific growth rate was calculated by linear regression of a logarithmic plot on the phase of constant and maximum values.

For yeast strains $6.7 \mathrm{~g} \mathrm{l}^{-1}$ Yeast Nitrogen Base medium (YNB, Difco Laboratories-Becton, Dickinson and Co., Sparks, MD, USA) was supplemented either with $50 \mathrm{~g} \mathrm{l}^{-1}$ galactose or $20 \mathrm{~g} \mathrm{l}^{-1}$ glucose as sole carbon source to assess growth. YNB liquid medium was buffered with potassium hydrogen phthalate $\left(10.21 \mathrm{~g} \mathrm{l}^{-1}\right.$ phthalate, $2.1 \mathrm{~g}$ $\left.\mathrm{l}^{-1} \mathrm{KOH}, \mathrm{pH} 5.5\right)$ [31]. For growth on plates $20 \mathrm{~g} \mathrm{l}^{-1}$ glucose and $20 \mathrm{~g}_{\text {agar }} \mathrm{1}^{-1}$ was used. The concentration of YNB was doubled when the sugar concentration was above $20 \mathrm{~g} \mathrm{l}^{-1}$ to avoid nutrient limitation. Pre-cultures grown in YNB with $20 \mathrm{~g} \mathrm{l}^{-1}$ glucose until mid-late exponential phase

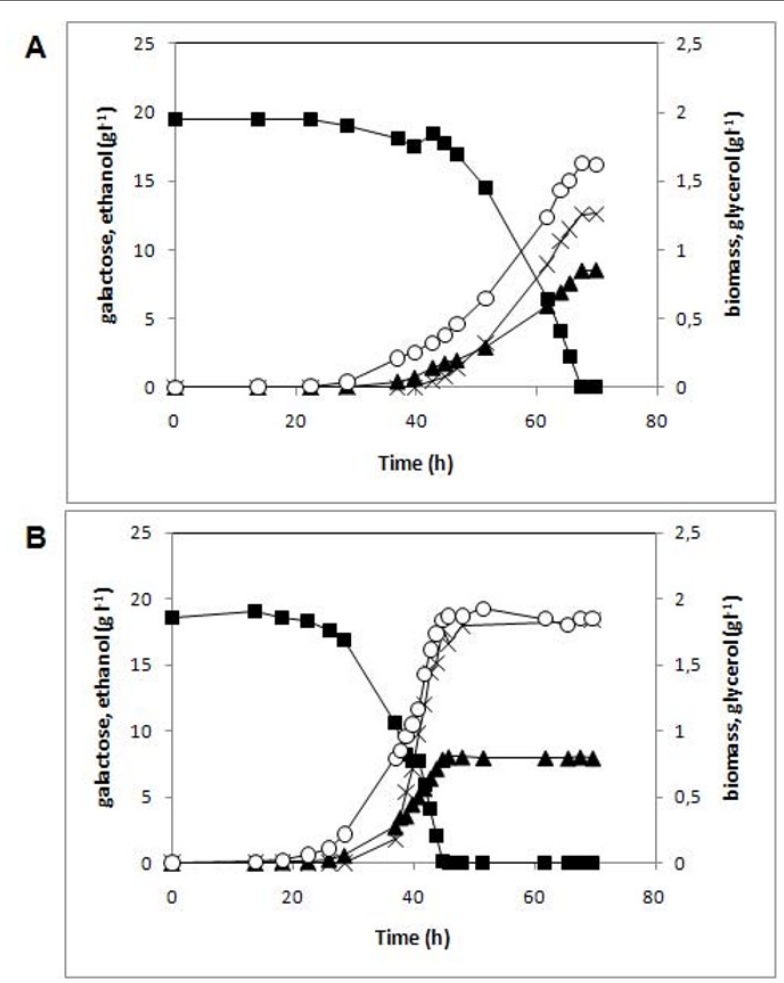

Figure 2 Effect of $P G M 2$ overexpression on anaerobic batch fermentation of galactose. Sugar consumption and product formation in anaerobic batch fermentation of $20 \mathrm{~g} \mathrm{I}^{-1}$ galactose in defined medium with strains (A) Control $i$ and (B) PGM2 i. Cells for inocula were pregrown in defined medium with $20 \mathrm{~g} \mathrm{l}^{-1}$ glucose. Experiments were performed in duplicate. Symbols: galactose (filled square), ethanol (filled triangle), biomass (DW) (open circle), glycerol (cross symbol). overnight in $50 \mathrm{ml}$ tubes were used to inoculate batch cultures at $\mathrm{OD}{ }_{620 \mathrm{~nm}}$ 0.1-0.2 in cotton-stoppered baffled $500 \mathrm{ml}$ flasks. To ensure initial aerobic conditions, the growth media was only $10 \%$ of the flask volume. YNB medium was supplemented with $40 \mathrm{mg} \mathrm{l}^{-1}$ histidine and $20 \mathrm{mg} \mathrm{l}^{-1}$ uracil for auxotrophic strains. Cultivation was performed at $30^{\circ} \mathrm{C}$ and $180-200 \mathrm{rpm}$ agitation (Gallenkamp INR-200, Leicester, UK) at least in duplicate.

\section{Anaerobic fermentation}

For anaerobic fermentation and corresponding pre-cultures defined mineral medium [32] was used. The medium for anaerobic fermentation was supplemented with $0.4 \mathrm{~g} \mathrm{l}^{-1}$ Tween 80 and $0.01 \mathrm{~g} \mathrm{l}^{-1}$ ergosterol and $20 \mathrm{~g} \mathrm{l}^{-}$ ${ }^{1}$ galactose. The pre-culture medium contained $20 \mathrm{~g} \mathrm{l}^{-1}$ glucose and was buffered with phthalate buffer $\left(10.21 \mathrm{~g} \mathrm{l}^{-}\right.$ ${ }^{1}$ phthalate, $2.1 \mathrm{~g} \mathrm{l}^{-1} \mathrm{KOH}, \mathrm{pH} 5.5$ ) [31] whereas the bioreactor $\mathrm{pH}$ was controlled at 5.5 with automatic addition of $3 \mathrm{M} \mathrm{KOH}$.

A first pre-culture was grown until late exponential phase in $50 \mathrm{ml}$ tubes. The culture was used to inoculate a second aerobic pre-culture in $1000 \mathrm{ml}$ cotton-stoppered baffled shake flasks. Both pre-cultures were grown in media, constituting $10 \%$ of vessel volume to assure maximum aeration. Cultures were grown at $30^{\circ} \mathrm{C}$ (Gallenkamp INR-200, Leicester, UK) and 180-200 rpm. Cells from the second pre-culture were grown until late exponential phase, washed twice with sterile water, centrifuged at $5000 \mathrm{rpm}$ for $10 \mathrm{~min}$, and used to inoculate anaerobic batch cultures at OD $620 \mathrm{~nm}$ of 0.1-0.2.

Anaerobic batch fermentation was performed in 31 Applikon Bio Reactors (Applikon, Schiedam, The Netherlands) with a working volume of $1.5 \mathrm{l}$, at $30^{\circ} \mathrm{C}$ and 200 rpm stirring. Prior to inoculation the bioreactor was flushed with nitrogen gas containing less than $5 \mathrm{ppm} \mathrm{O}_{2}$ (AGA Gas, Sundbyberg, Sweden) from the bottom of the bioreactor at a flow rate of $0.21 \mathrm{~min}^{-1}$ controlled by a gas mass flow-meter (Bronkhorst, HI-TECH, Ruurlo, The Netherlands). Outlet carbon dioxide and oxygen were monitored by a Carbon Dioxide and Oxygen Monitor type 1308 (Brüel \& Kjaer, Copenhagen, Denmark). Offgas condensers were cooled to $4^{\circ} \mathrm{C}$ to minimize ethanol 
evaporation and a dissolved oxygen probe monitored $0 \%$ oxygen tension. Anaerobic fermentation experiments were performed in at least biological duplicates and metabolite measurements varied with less than $10 \%$. Cultivation was performed both with and without nitrogen gas flushing. Flushing resulted in an increased lag phase but did not affect the outcome of the experiment. Physiological characterization of recombinant strains was only performed with the prototrophic strains.

\section{Enzymatic activity measurements}

PGM activity was determined in crude extracts of cells grown on YNB medium containing $20 \mathrm{~g} \mathrm{l}^{-1}$ galactose. For every strain, at least three independent biological replicates were assayed with at least two independent enzymatic measurements. Cells were harvested in exponential phase, centrifuged at $5000 \mathrm{rpm}$ for $5 \mathrm{~min}$, washed twice with cold sterile water and permeabilized with Y-PER (Pierce, Rockford, IL, USA). The protein concentration was determined with Coomassie Protein Assay Reagent (Pierce, Rockford, IL, USA), using bovine serum albumin as standard. Phosphoglucomutase activity was determined at $30^{\circ} \mathrm{C}$ by monitoring NAPDH production at 340 $\mathrm{nm}$ [13] with a Ultrospec 2100 pro spectrophotometer (Amersham Biosciences, Uppsala, Sweden). The chemicals used to determine enzyme activity were purchased from Sigma-Aldrich (St. Louis, MO, USA).

\section{Determination of metabolites and maximum specific growth rate}

Concentrations of galactose, glycerol, acetic acid and ethanol were determined by high-pressure liquid chromatrography (HPLC) (Waters, Milford, MA, USA or Beckman Instruments Fullerton, CA, USA) with an Aminex HPX-87H ion exchange column (Bio-Rad, Hercules, USA) at $45^{\circ} \mathrm{C}$. The mobile phase was $5 \mathrm{mM} \mathrm{H}_{2} \mathrm{SO}_{4}$ at a flow rate of $0.6 \mathrm{ml} \mathrm{min}^{-1}$. Cell dry weight was determined in at least duplicate at different time points of the fermentation experiment by filtering $5 \mathrm{ml}$ culture through a pre-weighed and microwaved dried hydrophilic polyethersulfone $0.45 \mu \mathrm{M}$ filter (PALL, Life Sciences, Michigan, USA). The filters were dried at $350 \mathrm{~W}$ for $8 \mathrm{~min}$ in a microwave oven and cooled prior to weighing.

The maximum specific growth rate was calculated by linear regression on a logarithmic plot of the phase of constant and maximum values.

\section{Competing interests}

The authors declare that they have no competing interests.

\section{Authors' contributions}

RGS participated in the design of the study, performed the experimental work and drafted the manuscript. BHH and MFGG designed the study and edited the manuscript. All authors read and approved the final manuscript.

\section{Acknowledgements}

The Swedish Energy Agency and the EU project NILE (New Improvements for Ligno-cellulosic Ethanol) financially supported the investigation.

\section{Author Details}

Department of Applied Microbiology, Lund University, P.O. Box 124, SE-22100 Lund, Sweden

Received: 4 March 2010 Accepted: 27 May 2010

Published: 27 May 2010

\section{References}

1. Sassner P, Galbe M, Zacchi G: Techno-economic evaluation of bioethanol production from three different lignocellulosic materials. Biomass and Bioenergy 2008, 32(5):422-430

2. Yu S, Wayman M, Parekh SK: Fermentation to ethanol of pentosecontaining spent sulphite liquor. Biotechnology and Bioengineering 1987, 29(9):1144-1150.

3. Sassner P, Galbe M, Zacchi G: Steam pretreatment of salix with and without SO2 impregnation for production of bioethanol. Applied Biochemistry and Biotechnology 2005, 121-124:1101-1117.

4. Söderström J, Pilcher L, Galbe M, Zacchi G: Two-step steam pretreatment of softwood with $\mathrm{SO} 2$ impregnation for ethanol production. Applied Biochemistry and Biotechnology 2002, 98-100:5-21.

5. Gasent-Ramírez JM, Codón AC, Benítez T: Characterization of genetically transformed Sacerevisiae baker's yeasts able to metabolize melibiose. Appl Environ Microb 1995, 61(6):2113-2121.

6. González Siso MI: The biotechnological utilization of cheese whey: A review. Bioresource Technology 1996, 57(1):1-11.

7. Rudolf A, Karhumaa K, Hahn Hägerdal B: Ethanol production from traditional and emerging raw materials. In Yeast Biotechnology: Diversity and Applications Volume 3. Springer Netherlands; 2009:489-513.

8. Leloir LF: The enzymatic transformation of uridine diphosphate glucose into a galactose derivative. Archives of Biochemistry and Biophysics 1951, 33(2):186-190

9. Gonçalves PM, Griffioen G, Bebelman JP, Planta RJ: Signalling pathways leading to transcriptional regulation of genes involved in the activation of glycolysis in yeast. Molecular Microbiology 1997, 25(3):483-493.

10. Johnston M: A model fungal gene regulatory mechanism: the GAL genes of Saccharomyces cerevisiae. Microbiological Reviews 1987, 51(4):458-476.

11. de Jongh WA, Bro C, Ostergaard S, Regenberg B, Olsson L, Nielsen J: The roles of galactitol, galactose-1-phosphate, and phosphoglucomutase in galactose-induced toxicity in Saccharomyces cerevisiae. Biotechnology and Bioengineering 2008, 101(2):317-326.

12. Ostergaard S, Olsson L, Johnston M, Nielsen J: Increasing galactose consumption by Saccharomyces cerevisiae through metabolic engineering of the GAL gene regulatory network. Nature Biotechnology 2000, 18(12):1283-1286

13. Bro C, Knudsen S, Regenberg B, Olsson L, Nielsen J: Improvement of galactose uptake in Saccharomyces cerevisiae through overexpression of phosphoglucomutase: example of transcript analysis as a tool in inverse metabolic engineering. Applied and Environmental Microbiology 2005, 71(11):6465-6472

14. Hauf J, Zimmermann FK, Muller S: Simultaneous genomic overexpression of seven glycolytic enzymes in the yeast Saccharomyces cerevisiae. Enzyme and Microbial Technology 2000, 26(910):688-698

15. Bevan P, Douglas HC: Genetic control of phosphoglucomutase variants in Saccharomyces cerevisiae. Journal of Bacteriology 1969, 98(2):532-8.

16. Oh D, Hopper JE: Transcription of a yeast phosphoglucomutase isozyme gene is galactose inducible and glucose repressible. Molecular and Cellular Biology 1990, 10(4):1415-1422.

17. Karhumaa K, Garcia Sanchez R, Hahn-Hägerdal B, Gorwa-Grauslund MF: Comparison of the xylose reductase-xylitol dehydrogenase and the xylose isomerase pathways for xylose fermentation by recombinant Saccharomyces cerevisiae. Microbial Cell Factories 2007, 6:5.

18. Brink J van den, Akeroyd M, Hoeven R van der, Pronk JT, de Winde JH, Daran-Lapujade P: Energetic limits to metabolic flexibility: responses of Saccharomyces cerevisiae to glucose-galactose transitions. Microbiology 2009, 155:1340-1350. 
19. Franco-Duarte R, Umek L, Zupan B, Schuller D: Computational approaches for the genetic and phenotypic characterization of a Saccharomyces cerevisiae wine yeast collection. Yeast 2009, 26(12):675-692.

20. Howard SC, Deminoff SJ, Herman PK: Increased phosphoglucomutase activity suppresses the galactose growth defect associated with elevated levels of Ras signaling in S. cerevisiae. Current Genetics 2006, 49(1):1-6.

21. Boles E, Heinisch J, Zimmermann FK: Different signals control the activation of glycolysis in the yeast Saccharomyces cerevisiae. Yeast 1993, 9(7):761-770

22. Müller S, Boles E, May M, Zimmermann FK: Different internal metabolites trigger the induction of glycolytic gene-expression in Saccharomyces cerevisiae. Journal of Bacteriology 1995, 177(15):4517-4519.

23. Sambrook J, Fritch E, T M: Molecular Cloning: A Laboratory Manual Cold Spring Harbor Laboratory Press: Cold Spring Harbor, NY; 1989.

24. Inoue HN, Okayama HH: High efficiency transformation of Escherichia coli with plasmids. Gene 1990, 96(1):23-28.

25. Dagert M, Ehrlich SD: Prolonged incubation in calcium chloride improves the competence of Escherichia coli cells. Gene 1979, 6(1):23-28.

26. Gietz RD, Schiestl RH, Willems AR, Woods RA: Studies on the transformation of intact yeast cells by the LiAc/SS-DNA/PEG procedure. Yeast 1995, 11(4):355-360

27. Karhumaa K, Hahn-Hägerdal B, Gorwa-Grauslund MF: Investigation of limiting metabolic steps in the utilization of xylose by recombinant Saccharomyces cerevisiae using metabolic engineering. Yeast 2005, 22(5):359-368.

28. Entian K, Kötter P: Yeast mutant and plasmid collections. In Yeast gene analysis Volume 26. Edited by: Brown JPA, Tuite MF. San Diego California Academic Press; 1998:431-449.

29. Wahlbom CF, van Zyl WH, Jonsson LJ, Hahn-Hägerdal B, Otero RR: Generation of the improved recombinant xylose-utilizing Saccharomyces cerevisiae TMB 3400 by random mutagenesis and physiological comparison with Pichia stipitis CBS 6054. FEMS Yeast Research 2003, 3(3):319-326.

30. Gietz RD, Sugino A: New yeast-Escherichia coli shuttle vectors constructed with in vitro mutagenized yeast genes lacking six-base pair restriction sites. Gene 1988, 74(2):527-534.

31. Hahn-Hägerdal B, Karhumaa K, Larsson CU, Gorwa-Grauslund M, Gorgens $J$, van Zyl WH: Role of cultivation media in the development of yeast strains for large scale industrial use. Microbial Cell Factories 2005, 4:31.

32. Jeppsson M, Bengtsson O, Franke K, Lee H, Hahn-Hägerdal B, GorwaGrauslund MF: The expression of a Pichia stipitis xylose reductase mutant with higher K(M) for NADPH increases ethanol production from xylose in recombinant Saccharomyces cerevisiae. Biotechnology and Bioengineering 2006, 93(4):665-673.

33. Berben G, Dumont J, Gilliquet V, Bolle PA, Hilger F: The YDp plasmids: a uniform set of vectors bearing versatile gene disruption cassettes for Saccharomyces cerevisiae. Yeast 1991, 7(5):475-477.

doi: $10.1186 / 1475-2859-9-40$

Cite this article as: Garcia Sanchez et al., PGM2 overexpression improves anaerobic galactose fermentation in Saccharomyces cerevisiae Microbial Cell Factories 2010, 9:40

\section{Submit your next manuscript to BioMed Central} and take full advantage of:

- Convenient online submission

- Thorough peer review

- No space constraints or color figure charges

- Immediate publication on acceptance

- Inclusion in PubMed, CAS, Scopus and Google Scholar

- Research which is freely available for redistribution

Submit your manuscript at www.biomedcentral.com/submit
C Biomed Central 